\title{
Feasibility, safety, and utility of bronchoscopy in patients with ARDS while in the prone position
}

\author{
Or Kalchiem-Dekel ${ }^{1 *}$ D, Carl B. Shanholtz ${ }^{1}$, Jean Jeudy², Ashutosh Sachdeva ${ }^{1}$ and Edward M. Pickering ${ }^{1}$
}

Prone positioning (PP) was shown to reduce mortality in mechanically ventilated (MV) patients with severe ARDS [1]. Despite its common use, safety concerns inhibit use of flexible bronchoscopy (FB) in patients with ARDS, and there are few reports of FB performed in PP [2]. We reviewed all adults receiving FB in PP in one institution between April 2016 and September 2017. The study was approved by the institutional review board. Four men and three women were identified (Table 1). In five patients, FB was indicated for clearance of thick secretions, and in two patients for microbial analysis. The mode of mechanical ventilation was not changed for $\mathrm{FB}$, but $\mathrm{FIO}_{2}$ was universally set to $100 \%$. All subjects had invasive hemodynamic and pulse oximetry monitoring. End-tidal carbon dioxide $\left(\mathrm{EtCO}_{2}\right)$ was monitored in $3 / 7$ subjects. With the subject's head tilted to the side, the bronchoscope was advanced into the airways, repeatedly, and in short cycles, allowing time for oxygenation, ventilation, and lung recruitment between insertions. Therapeutic aspiration was performed in 6/7 subjects. Bronchoalveolar lavage was performed in two subjects. No significant hemodynamic compromise was observed during any of the procedures. Significant oxygen desaturation and rising $\mathrm{EtCO}_{2}$ were observed in one case (patient 4 ). Both derangements resolved with withdrawal of the bronchoscope and recruitment. No additional complications were documented. Figure 1 illustrates evolution of the $\mathrm{PaO}_{2}: \mathrm{FIO}_{2}$ ratio over time for each subject. Six subjects had antibiotics modified based on FB-obtained cultures. Consistent with previous data [3], 4/7 subjects survived 30 days following discharge from the ICU.

Although PP is lung-protective, it may result in mobilization of secretions into the airways, impairing oxygenation and providing nidus for infection [4]. Despite documented risks [5], FB may be beneficial in this situation.

Several limitations need to be addressed when interpreting our data. This is a retrospective analysis. Although physiologic monitoring was automatically captured, ventilator data were not and ventilator output during FB could not be accurately analyzed. Additionally, $\mathrm{EtCO}_{2}$ was not measured in all cases during FB. Finally, PP was shown to reduce mortality in patients with moderate to severe ARDS, however, our study subjects' oxygenation had started to improve by the time FB was performed (Fig. 1, T1). This likely reflects reluctance to perform FB in subjects with severe hypoxemia due to excessive risks.

Our report demonstrates the feasibility of FB performed in brief increments in carefully monitored patients with ARDS ventilated in PP. Further studies are needed to better delineate optimal ventilator management during FB in PP.

\footnotetext{
* Correspondence: orkalchiemdekel@umm.edu

${ }^{1}$ Division of Pulmonary, Critical Care, and Sleep Medicine, University of Maryland School of Medicine, 110 South Paca Street, Baltimore, MD 21201, USA

Full list of author information is available at the end of the article
} 
Table 1 Individual patient parameters, flexible bronchoscopy performance, and outcomes $(n=7)$

\begin{tabular}{|c|c|c|c|c|c|c|c|}
\hline Variable & Patient 1 & Patient 2 & Patient 3 & Patient 4 & Patient 5 & Patient 6 & Patient 7 \\
\hline Age (years) & 63 & 18 & 44 & 79 & 53 & 23 & 61 \\
\hline Sex & Female & Female & Male & Male & Male & Female & Male \\
\hline Ethnicity & Black & Caucasian & Caucasian & Asian & Caucasian & Black & Caucasian \\
\hline Etiology of ARDS & MRSA sepsis & $\begin{array}{l}\text { Massive } \\
\text { pulmonary } \\
\text { embolism }\end{array}$ & $\begin{array}{l}\text { Fulminant } \\
\text { hepatic failure, } \\
\text { Klebsiella sepsis }\end{array}$ & Pneumonia & $\begin{array}{l}\text { Massive } \\
\text { aspiration }\end{array}$ & $\begin{array}{l}\text { Massive } \\
\text { aspiration }\end{array}$ & Pneumonia \\
\hline $\begin{array}{l}\text { Total ICU LOS (days)/day } \\
\text { of FB }\end{array}$ & $27 / 9$ & $30 / 13$ & $97 / 32$ & $35 / 29$ & $9 / 2$ & $49 / 11$ & $16 / 1$ \\
\hline $\begin{array}{l}\text { Prone-positioning protocol } \\
\text { (total hours) }\end{array}$ & 28 & 18 & 16 & 236 & 20 & 133 & 18 \\
\hline $\begin{array}{l}\text { 30-day survival post ICU } \\
\text { discharge }\end{array}$ & No & Yes & Yes & No & Yes & Yes & No \\
\hline \multicolumn{8}{|l|}{$\begin{array}{l}\text { Ventilator-related parameters } \\
\text { at } \mathrm{FB}^{\mathrm{a}}\end{array}$} \\
\hline Mode & PRVC & PC/AC & $\mathrm{VC} / \mathrm{AC}$ & PRVC & $\mathrm{VC} / \mathrm{AC}$ & PC/AC & $P C / A C$ \\
\hline Peak pressure $\left(\mathrm{cmH}_{2} \mathrm{O}\right)$ & 32 & 29 & 24 & 37 & 30 & 20 & 32 \\
\hline Plateau pressure $\left(\mathrm{cmH}_{2} \mathrm{O}\right)$ & 27 & NA & NA & 30 & 26 & NA & 27 \\
\hline PEEP $\left(\mathrm{cmH}_{2} \mathrm{O}\right)$ & 11 & 12 & 15 & 8 & 10 & 10 & 14 \\
\hline $\mathrm{FlO}_{2}(\%)$ & 100 & 100 & 100 & 100 & 100 & 100 & 100 \\
\hline \multicolumn{8}{|l|}{ FB-related data } \\
\hline $\begin{array}{l}\Delta \text {-diameter ETT to } \\
\text { bronchoscope }(\mathrm{mm})\end{array}$ & 1.7 & 2.0 & 1.7 & 2.0 & 2.0 & 4.0 & 3.1 \\
\hline Therapeutic aspiration & Yes & Yes & Yes & No & Yes & Yes & Yes \\
\hline Bronchial washings / BAL & Yes & Yes & Yes & Yes & Yes & Yes & Yes \\
\hline \multicolumn{8}{|l|}{ Monitoring data } \\
\hline \multicolumn{8}{|l|}{ MAP } \\
\hline Baseline $^{a}$ & 69 & 67 & 87 & 68 & 72 & 67 & 80 \\
\hline Trough during FB & 69 & 64 & 72 & 66 & 71 & 67 & 68 \\
\hline \multicolumn{8}{|l|}{$\mathrm{SpO}_{2}$} \\
\hline Baseline $^{a}$ & 94 & 98 & 97 & 100 & 100 & 100 & 100 \\
\hline Trough during FB & 94 & 92 & 97 & 87 & 99 & 99 & 100 \\
\hline \multicolumn{8}{|l|}{$\mathrm{EtCO}_{2}$} \\
\hline Baseline $^{a}$ & 48 & 30 & NA & 43 & NA & NA & NA \\
\hline Trough during FB & 49 & 30 & NA & 51 & NA & NA & NA \\
\hline $\begin{array}{l}\text { Change in antibiotic regimen } \\
\text { based on culture results }\end{array}$ & De-escalation & De-escalation & No & Additional coverage & De-escalation & De-escalation & De-escalation \\
\hline
\end{tabular}

ARDS adult respiratory distress syndrome, ICU intensive care unit, $L O S$ length of stay, FB flexible bronchoscopy, MRSA methicillin-resistant Staphylococcus aureus, PRVC pressure-regulated volume control, $P C / A C$ pressure-cycled assist-controlled, VC/AC volume-cycled assist-controlled, $P E E P$ positive end-expiratory pressure, $E T$ endotracheal tube, $B A L$ bronchoalveolar lavage, MAP mean arterial pressure as measured with an arterial line, $\mathrm{NA}$ not available, $\mathrm{SpO}_{2}$ oxygen saturation as measured with pulse oximetry, $\mathrm{EtCO}_{2}$ end-tidal carbon dioxide, $\mathrm{FIO}_{2}$ fractional concentration of inspired oxygen

${ }^{\mathrm{a}}$ As documented prior to first bronchoscope insertion 


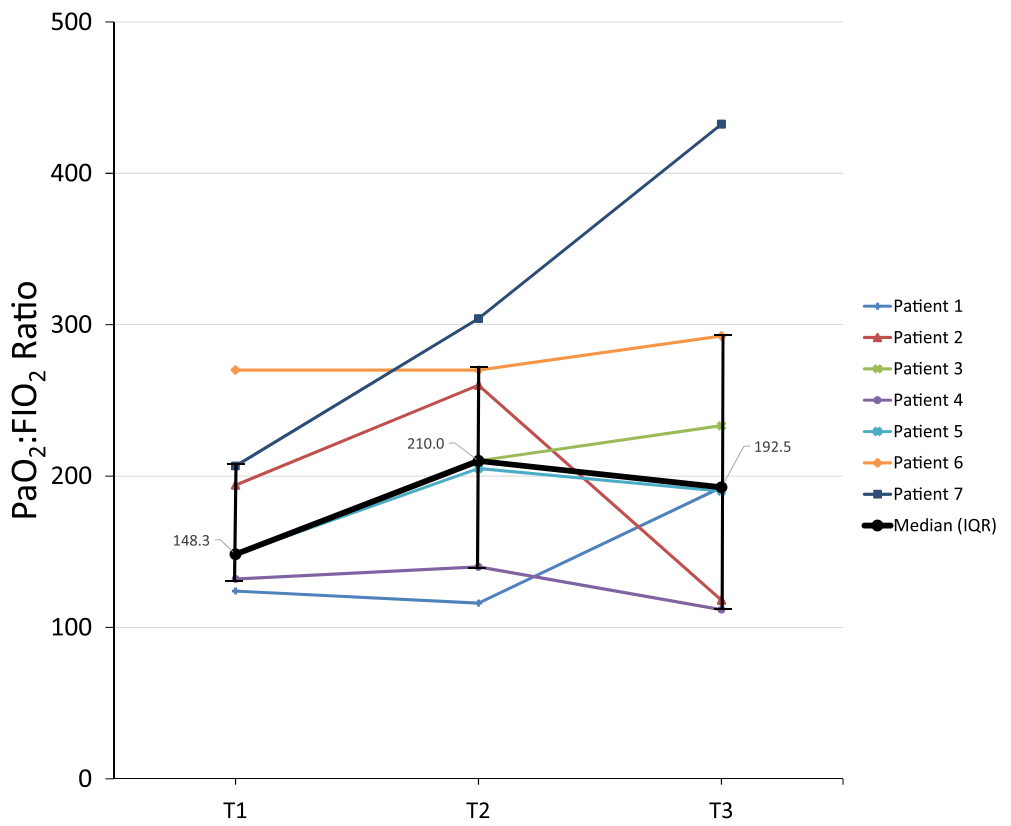

Fig. 1 Evolution of $\mathrm{PaO}_{2}$ to $\mathrm{FIO}_{2}$ ratio from pre bronchoscopy (T1) to $24 \mathrm{~h}(\mathrm{~T} 2)$ and $72 \mathrm{~h}$ (T3) post bronchoscopy $(n=7)$. IQR interquartile range, $\mathrm{PaO}_{2}$ partial pressure of arterial oxygen, $\mathrm{FlO}_{2}$ fractional concentration of inspired oxygen

\section{Abbreviations}

ARDS: Acute respiratory distress syndrome; $\mathrm{EtCO}_{2}$ : end-tidal carbon dioxide; FB: Flexible bronchoscopy; $\mathrm{FIO}_{2}$ : Fraction of inspired oxygen; ICU: Intensive care unit; MV: Mechanical ventilation; $\mathrm{PaO}_{2}$ : Partial pressure of arterial oxygen; PP: Prone position

\section{Acknowledgements}

This manuscript was presented as a thematic poster during the American Thoracic Society International Conference, Washington DC, USA, May 2017.

\section{Funding}

This research received no specific grant from any funding agency in the public, commercial, or not-for-profit sectors.

\section{Availability of data and materials}

The datasets used and/or analyzed during the current study are available from the corresponding author on reasonable request.

\section{Authors' contributions}

OK-D, AS, and EMP contributed to the study concept and design. OK-D, CBS, $A S$, and EMP contributed to acquisition of data. OK-D, CBS, JJ, AS, and EMP contributed to analysis and interpretation of data. OK-D contributed to drafting of the manuscript. All declared authors contributed to critical revision of the manuscript for important intellectual content. All authors read and approved the final manuscript.

\section{Ethics approval and consent to participate}

The study was conducted at University of Maryland Medical Center in accordance with Good Clinical Practice (Declaration of Helsinki 2002) and University of Maryland, Baltimore Campus Institutional Review Board approvals (IRB reference number HP-00073462). Patients were included from April 2016 to September 2017. A waiver of consent has been approved per 45 CFR 46.116(d).

\section{Consent for publication}

Not applicable.

\section{Competing interests}

The authors declare that they have no competing interests.

\section{Publisher's Note}

Springer Nature remains neutral with regard to jurisdictional claims in published maps and institutional affiliations.

\section{Author details}

${ }^{1}$ Division of Pulmonary, Critical Care, and Sleep Medicine, University of Maryland School of Medicine, 110 South Paca Street, Baltimore, MD 21201, USA. ${ }^{2}$ Department of Diagnostic Radiology and Nuclear Medicine, University of Maryland School of Medicine, 110 South Paca Street, Baltimore, MD 21201, USA.

Received: 31 January 2018 Accepted: 7 February 2018 Published online: 02 March 2018

\section{References}

1. Guerin C, Reignier J, Richard J-C, Beuret P, Gacouin A, Boulain T, Mercier E, Badet M, Mercat A, Baudin O, Clavel M, Chatellier D, Jaber S, Rosselli S, Mancebo J, Sirodot M, Hilbert G, Bengler C, Richecoeur J, Gainnier M, Bayle F, Bourdin G, Leray V, Girard R, Baboi L, Ayzac L. Prone positioning in severe acute respiratory distress syndrome. N Engl J Med. 2013;368(23):2159-68.

2. Guarracino F, Bertini P, Bortolotti U, Stefani M, Ambrosino N. Flexible bronchoscopy during mechanical ventilation in the prone position to treat acute lung injury. Rev Port Pneumol. 2013;19(1):42-4.

3. Bellani G, Laffey JG, Pham T, Fan E, Brochard L, Esteban A, Gattinoni L, van Haren F, Larsson A, McAuley DF, Ranieri M, Rubenfeld G, Thompson BT, Wrigge H, Slutsky AS, Pesenti A. Epidemiology, patterns of care, and mortality for patients with acute respiratory distress syndrome in intensive care units in 50 countries. JAMA. 2016;315(8):788-800.

4. Graf J, Marini JJ. Do airway secretions play an underappreciated role in acute respiratory distress syndrome? Curr Opin Crit Care. 2008;14(1):44-9.

5. Steinberg KP, Mitchell DR, Maunder RJ, Milberg JA, Whitcomb ME, Hudson LD. Safety of bronchoalveolar lavage in patients with adult respiratory distress syndrome. Am Rev Respir Dis. 1993;148(3):556-61. 